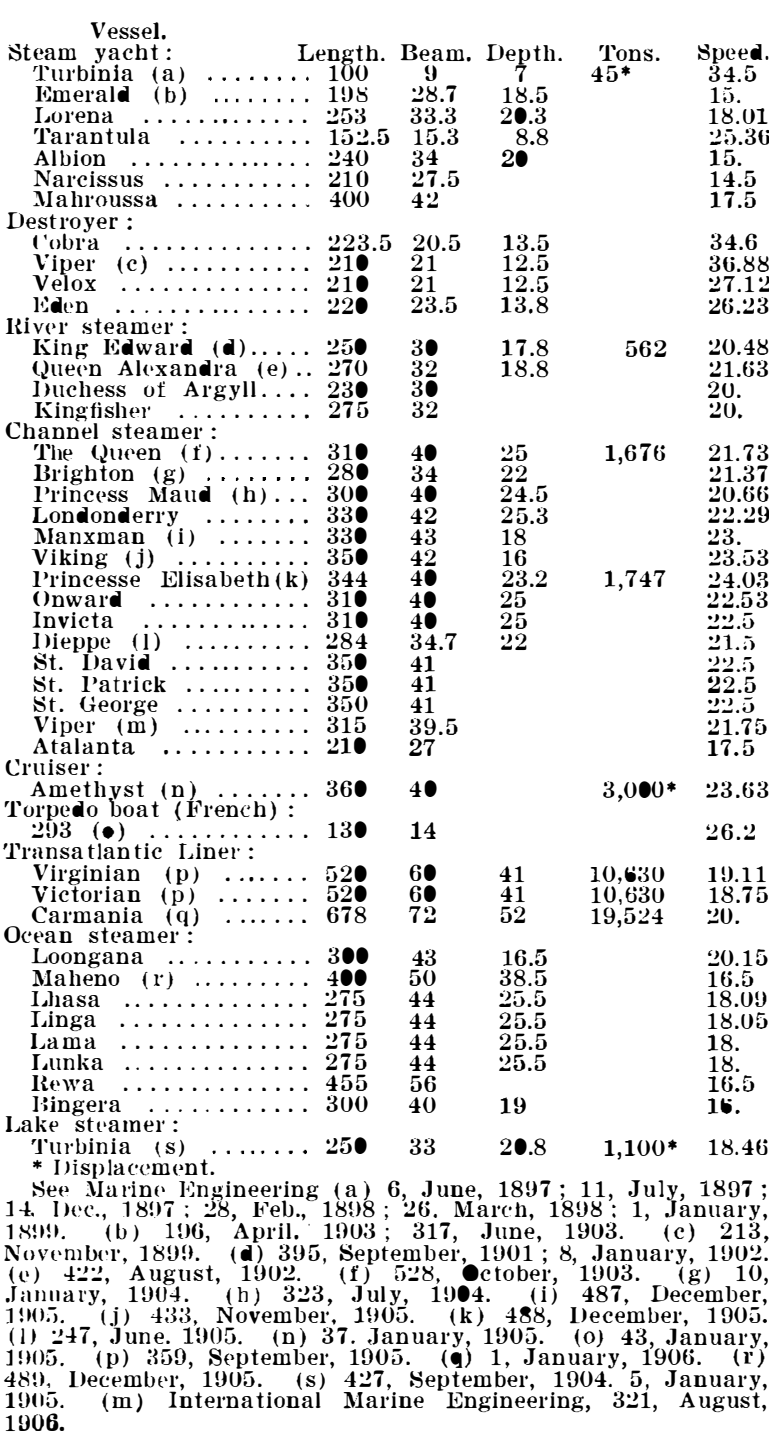

of new vessels to defer the adoption of a new system until the claimants had results to show.

The Parsons turbine was introduced to the Continen by the small French torpedo boat "No. 293." This boat ordered by the French navy as an experiment in the year 1903 , has been in continual service for over two years without any breakdown or repair, and continues tc give in practice the results obtained on trial. Natu-
rally, so small a boat hardly demonstrates the results rally, so small a boat hardly demonstrates the results
which might be expected from larger installations. which might be expected from larger installations. by 14 feet, and of 95 tons displacement. She attained a speed of 26.2 knots. The arranzement of machinery is similar

In France, a mail and passenger boat is being built for the Marseilles and Algiers service of the Com pagnie Generale Transatlantique. She is 378 by 43
feet, and is designed for a service speed of 20 knots. feet, and is designed for a service speed of 20 knots.
In the United States five passenger vessels are being built, and a scout cruiser of 24 knots speed for the government, to be fitted with Parsons turbines.

Reference to the table will show the vessels which have been engined in Great Britain with Parsons tur bines up to the present date, representing a total horsenower actually completed of about 280,000 . The total
horse-power of marine turbine engines completed and on order with the Parsons Marine Company and their licensees is over 870,000 .

I EVELOPMENT IN THE EXPLOSIVES ART IN THE UNITED STATES DURING THE LAST FIVE YEARS.*

By Charles E. Munroe, Ph.D., Professor of Chemistry, George Washington University.

In my report on the progress of the explosives in dustry of the United States made at Berlin, I was able to give statistical data from the census of manufactures for 1900 , but though by law this census is now to be taken each fifth year, the returns for the census of 1905 are not yet reduced to such a condition that they may be cited. In lieu of this we have an estimate collected by an independent canvass, from which it appears that $346,841,891$ pounds of explosives of all kinds were manufactured in the United States in 1904 . As the total reported for 1900 was $215,980,719$ pounds, we have a gain in about five years

pounds, representing 62.27 per cent. This estimate was made in connection with an inexplosives. Owing to the peculiar form of government existing in the United States, the federal law is of the most general character and is practically limited to prohibiting, under penalty, the transportation of certain explosives in any vehicle carrying passengers. The separate States have power to make their own laws regulating this traffic, and many have done so, while a considerable number of cities have enacted special ordinances. But not all States or cities have made regulations, and there is a wide diversity in the laws and ordinances of the several States and cities. The regulations which are equally diverse in character. Some of these railroads refuse to transport any exothers accept explosives only on particular days; oth * Read at S1xth International Congress of Apphed Chemistry in Rome,
April 13, 1906. ers accept high explosives only in carload lots. This
confusion in laws, ordinances, and regulations perconfusion in laws, ordinances, and regulations perplexes the manufacturer,

expensive and dangerous.
Accidents have occurred from time to time in manuacture, storage, and transportation, and as they have attracted attention repeated efforts have been made to secure reasonable and uniform regulations by which to control transportation and reduce the chance of accidents. An accident during transportation, which
occurred on the railroad near Harrisburg, was of unoccurred on the railroad near Harrisburg, was of unusual magnitude and attended with many fatalities, and this served to arouse public opinion to such an extent that a body representing the major number of the railroad corporations, and styled the American Railway Association, appointed a Committee on Transportation of Explosives and employed three experts in explosives to advise with them, with the result that a set of
regulations embodying the best results of experience regulations embodying the best results of experience lated, and in September last submitted to the railroads of the country for adoption. The prospect now is that these regulations will be very generally put into operation. Especial effort is

During the consideration of the various problems before the committee, it was deduced that taking the total output for the year as stated above, and a carload as 20,000 pounds, there was produced 17,342 carloads during the year, or a little over 47 full carloads per day, all of which is transported away from the works in which it is manufactured, and most of it by railroad. However, much of this is transported in less than carload lots, especially from central depositories or magazines. From observation and experience railroad officials estimate that the cars carrying small lots are five times as numerous as those carrying the full load, hence we have 330 cars per day loaded with explosives. It is estimated that on the average ten days are required in which to transport and deliver these consignments, therefore there will be each day on the railroads throughout the United States an average of 3,300 cars carrying explosives, and during the busy seasons and at special locations they will be especially numerous. The surprise is not that accidents do occur, but that they occur so infrequently. The inference is that notwithstanding the lack of retransportation has been intrusted have performed their duties in an intelligent and vigilant manner.

A marked change in the methods of conducting the explosives business to be noted is the union of interests of many of the larger manufacturers under the leadership of the famous Du Pont Company. By this means greater economies in manufacture are effected, while it has become possible to enter on a large scale into the manufacture of the raw materia's, such as nitric, sulphuric, and mixed acids, which are used in the making of explosives, availing themselves of the contact process and other modern improvements in these arts. At the same time research laboratories on modern lines have becn founded, and expert chemists and engineers employed to develop manufacture on scientific lines. Nevertheless, there are still many independent companies, and competition is keen. The United States turernment is especially concerned with the manufacture of military smokeless powder, and while it receives the major portion of its supplies from private the Nacturers, it possesses two factories controlled by from the present Congress for the erection of others to be under the control of the War Department.

A detail which has affected yields and costs in the dynamite industry is the introduction of ice machines for use in the manufacture of nitro-glycerine. By the use of artificial refrigeration the yield of nitro-glycerhe from a given mass of acid is increased, the speed is decreased, ind the danger attending nitration unnecessary. Two methods of refrigeration may be used: (1) The direct expansion system, in which cort.pressed ammonia is sent directly through the coils; and (2) the brine system, in which the ammonia is sent through the coils in a brine tank, and then the cooled brine is sent through the cooling coils in the nitrator or separator. The brine or indirect system is to be prerise of temperature would be less from the escape of a given mass of calcium chloride brine than from the escape of the same mass of ammonia; leakage of the that of the compressed and liquefied ammonia; less ammonia is required in the indirect than in the direct system, and the indirect system is a better one for dis. continuous use.

The quantities of acids and glycerine and the composition of the mixed acids vary somewhat in practice, but the advantage of artificial refrigeration may be illustrated by a concrete example, in which the charge of mixed acid is 6,400 pounds and its composition is
$\mathrm{H}_{2} \mathrm{SO}_{4}$
61.50 per cen
$\mathrm{H}_{2} \mathrm{O}$
4.00 per cent

With such a charge using the approved method of nitration without refrigeration, 880 pounds of glycerine may be nitrated and $1,953.6$ pounds of nitro-glycerine pounds of nitro-glycerine or an increased yield of 162.24 pounds will be obtained. With glycerine at 11 cents per pound and nitro-glycerine at 15 cents per pound, the increased profit from a single run is $\$ 19.05$, or for
four runs per day, which can be easily effected, a profit of $\$ 76.20$. As a 30 -ton machine ean be easily installed for $\$ 12,000$, and the cost of operation, including interest and 10 per cent depreciation, will not exceed $\$ 6,000$ per year, ther

At the same time we are far from realizing the theoretical conditions of efficiency, for the charge of acid cited above is theoretically sufficient to nitrate $1,074.77$ pounds of glycerine and to yield 2,651.31 pounds of nitro-glycerine, or 535.07 pounds more than is obtained by artificial refrigeration. I have, many years ago, advised my clients to thoroughly dry the air injected into the nitrator. Combined with refrigeration such dry air ought to enable us to approach more nearly
to the theoretical yield, but $I$ have as yet no data on this subject.

It is well known that at times the separation of the nitro-glycerine from the emulsion in the acid mixture in which it is formed is extremely slow. Dr. Charles: L. Reese alleges that this is due to the presence of silicon compounds, and he overcomes this diffculty by the addition of a fraction of a per cent of sodium fluoride before nitration, thereby forming silicon fluoride, which is eliminated by volatilization.

For the census year 1900 the smokeless powder of all kinds made in the United States amounted to but $3,053,126$ pounds, having a value of $\$ 1,716,101$. While, as stated above, no figures are yet available for 1905 , yet it is believed that there has been a great increase in production of both military and sporting smokeless powders. A notable change in practice has been in powder by the army and the adoption of a straight. nitro-cellulose powder of definite nitrogen content, thus bringing their practice into conformity with that of the navy. In fact, the continued tendency in military powders is to approach more closely to the principle set forth by the writer many years ago as govern. composed of a single chemical substance in a state of chemical purity."

The progress in smokeless sporting powder has been characterized by the adoption of a small-grained nitro. cellulose powder, which is gelatinized and then hardened throughout, in place of the grain which has heretofore been in pretty general use, and which was superficially gelatinized and hardened. The manufacture of such powder is carried out in a stationary vertical the lower end is a steam jacket, by which the contents of the vessel may be heated. A rotatable shaft extends downward through a stuffing box in the top of the vessel, or still, to a point near its bottom, and carries six arms extending across it, each arm being attached at its central point to the shaft and at points on the shaft about eight inches apart, and the ends of the arms reach nearly to the wall of the still. Five of the bars are square in cross-section and about one inch thick; the sixth bar, which is the upper one, is flatdirection so as to form paddles, which slant in the smooth down the surface of the liquid which is placed in the still.

An orifice at the bottom of the still having been first closed, the vertical shaft carrying its horizontal stirrers is set in rotation, and continued in rotation during the whole of the process at a speed sufficient suspension the particles of guncotton in mechanical are introduced into the still as hereincotton and water Water in which five per cent of barium nitrate and two per cent of saltpeter have been dissolved is then pumped into the still, through a pipe provided for this purpose, until the still has been partly filled. Finelypulped wet guncotton is then thrown into the still through an opening in the side of its upper part, this guncotton not having been as yet subjected to the action of any solvent. More water in which barium nitrate and saltpeter have been dissolved is then pumped into the still until the surface of the liquid in the still is about on a level with the upper stirrer blades on the vertical shaft. The opening through which the guncotton was inserted is now closed, and a previously-formed emulsion of from 25 to 50 per cent saltpeter in solution is pumped into the still.

The material now begins to granulate, and the progress of the granulation is observed by withdrawing a little of the mixture through a small orifice near the bottom of the still; and when granulation has been effected throughout the mass, which is within about the still the still was begun, steam is turned into the jacket
surrounding the lower portion of the still. The heating due to the steam is continued for a period of five or six hours, and during this time the amyl acetate is distilled and passes over, with the vapors from the
heated water, into a reservoir where the water is separated from it.

After the amyl acetate is thus removed a gate valve in the bottom of the still is opened, and the mixture of water and granulated powder is discharged from the sized, blended, and packed. The strength and the amount of the emulsion used depend upon the amount and quality of the guncotton, and the best proportions are ascertained by experience. The length of time amyl acetate used and the temperature of the steam in the steam jacket.

The still may measure about 6 feet 3 inches from its bottom to the upper stirrer blades, and about 5 feet in diameter in its cylindrical portion. In such a 
vessel the usual charge of guncotton is 405 pounds, to which is added the dust or very small grains from
previous granulations, making a total charge of upprevious granulations, making a total charge of up-
ward of 700 pounds. The finished powder is colored to suit the taste of the consumers.

Although active efforts have been made to introduce safety explosives into commercial use in the United States, and though joveite, which is an excellent ex-
plosive of this type, has received the highest enplosive of this type, has received the highest en-
comiums for safety and efficiency from engineers an explosive experts who have observed it in use under a sorts of conditions for over ten years, yet the fact that slightly more care must be taken in loading and priming shot holes to insure explosion where a safety explosive is used than when dynamite is employed,
and that strong caps must be used, has been sufficient and that strong caps must be used, has been sufficien to prejudice miners against the use of safety explos ives; notwithstanding that they commend themselves
to the mine owners. The chief thought of the miner seems to be to do his allotted task in the quickest manner and with the least effort.

\section{THE TWENTIETH CENTURY PEN.*}

By W. R. STEWART.

THE pen which seemed mightier than the sword to Lord Lytton was a very simple affair to make, com-
pared with that which the writer of the present day pared with that which the writer of the present day
employs. Although, to the eye, the ordinary steel pen of 1906 is not a particularly complicated instrument yet no fewer than twenty distinct operations enter into its making. That the completed product can be sold at a retail price of about two-thirds of a cent a pen is striking testimony to the delicate perfection of the machinery employed. To make a fountain pen no fewer than one hundred, and in some cases more operations are required. The gold nib alone represents sixty or are required. The gold nib alone

It was not until 1800 that the first steel pen made in the United States pushed its tentative way across paper, guided by the hand of one Peregrine Williamlater that the first steel pens were manufactured by mechanical process in this country. There had been a few made in England as early as 1820, but they wer far from being the flexible instrument they have since ecome, and their cost was excessively high.

During last year about two hundred and eighty-five million pens-steel, gold, and fountain, or stylographic -were manufactured in the United States. Fifty establishments were engaged in the pen industry in the United States last year, and the wholesale value of
their products was somewhat in excess of two million dollars. About four thousand wage-earners, largely dollars. About four thousand wage-earners, largely
women, were employed in the different factories. Of the total production of pens, about 54
manufactured in the State of New York.

of the three general varieties of pens now made, those of steel are, naturally, produced in by far the greatest number, contributing about $270,000,000$ of the total production of $285,000,000$ pens for the United
States during 1905 . In point of value however, the States during 1905 . In point of value however, the
steel pens represented only $\$ 300,000$, as against $\$ 820$, 000 worth of gold pens, and more than a million dollars' worth of fountain and stylographic pens.

Let us consider first the steel pen. Just who the real inventor of the steel pen was is unknown, the
honor being claimed for both an Englishman and a Frenchman, as well as for the jeweler of Baltimore The pens first produced by mechanical process in Eng-
land consisted simply of a piece of steel formed into a land consisted simply of a piece of steel formed into a
tube and filed into shape by hand, the joint of the two edges forming the slit. The product was expensiv and unsatisfactory, for the pen was hard and inflexible. By degrees presses were contrived for cutting, bend-
ing, and marking, and other machinery for cleaning and polishing.

The material now used for all kinds of steel pens is cast steel of the best quality, and as this has not yet
been produced successfully in the United States, it is imported from England and Sweden. This steel is received at the pen factory in sheets of various
lengths, widths, and thicknesses. It is there prepared for conversion into pens by a preliminary process of annealing (heating nearly to fluidity and then cooling slowly in order to render less brittle), polishing, an rolling. These operations need not be described, though that of rolling requires much care and skill, for the steel must be passed between successive rollers
until reduced to a required thickness, which is usually until reduced to a required thickness, which is usually the $1 / 160$ of an inch. The variation of one-thousandth part of an inch in the thickness of the strip would seri-
ously affect the flexibility of the pen. After emerging from the rollers, the strips are about three times their original length, and have a bright surface.

The process of forming and shaping the pen begins at this point, and in this work mostly women and girls are employed, on account of their greater dexterity of hand. A die and a punch are used to cut out the blank strips from which the pens are to be made. The die is set in a supporting frame or bolster, and is perforated by a hole the exact shape of the required blank. A punch, also of the exact shape of the blank, One of the strips of steel is then introduced by the operator, using her left hand, at the back of the press, and the handle pulled toward her with the right hand.
This causes the screw to descend, driving the punch into the bed and perforating the strip of steel, making a blank which falls through the opening in the die into a drawer underneath. This operation
until the whole of the strip is perforated.

* Spectially prepared for the Scientific Aakikican Mi 'PPT,KMEnt.
The next stage in the making of the pen is stamping or marking it with whatever name or number it is to
bear. This mark is cut upon a piece of steel, which is placed in the hammer of a stamp, the latter being operated by foot power. A handful of blanks is taken by the operator in the left hand, and a little train made
of them between the thumb and finger. With the right hand the blanks then are placed, one after the other in a guide upon the bed of the stamp, where the ham mer forthwith falls upon it, giving it the impression cut on the punch. As many as twenty thousand pen
can thus be stamped by a skillful operator in a day. The small hole which terminates the slit in the finished pen and prevents it from spreading, as well as producing the elasticity required and causing the ink to attach itself to the pen, is next pierced. To do this a piercing nunch and bed, made with great precision,
are fixed in a screw press, to which an ingenious arare fixed in a screw press, to which an ingenious arrangement of guides has been attached. The blank is
then placed in the proper position and the machinery manipulated so as to cause the screw to descend, driv ing the punch into the bed.

The blanks are now annealed so that they become pliable, and assume readily the various shapes into which they are to be made. A punch and die are again called into requisition, and the process which they perform in shaping the pen is called raising. After being given their curved form, the blanks are hardened by plunging in hot oil. They are next cleaned in sand and sawdust and tempered. The cleaning, or polish
ing, is accomplished by placing the pens in revolving barrels of sand or sawdust, and then grinding against a revolving emery wheel. The tempering is done by placing the pens in an iron cylinder, which is kept revolving over a charcoal fire until they are of the proper temper. This process is one of considerable delicacy, peing regulated according to the color shown by the
pendicates the varying temperatures of the metal.

The last mechanical operation upon the pen is, perhaps, the most important. This is the slitting of the point, which is done by a specially constructed pair of These equal in delicacy to the cutting edge of a razor about $1 \frac{1}{2}$ inches long. $3 / 7$ inch thick, and $11 / 4$ inches wide. One of the cutters is fixed in a press with a pair held by a bolster, to which is attached a small tool called a rest or table. The pen is placed by the operator on the table, the point pushed up toward the the lower one, thus slitting the pen. A final burnishing, and possibly lacquering, completes the pen, the rust.

So much for the making of steel pens. But gold and fountain pens are being manufactured in constantly of which is that they possess a greater durability and flexibility than pens made of steel, there were pro-
duced in the United States about a million during last year.

To a watchmaker of Detroit belongs the distinction of having first commenced the manufacture of gold was soon moved to New York. Before 1835 several attempts had been made in England to make gold pens, but they had met with little success. At first the points of gold pens were protected by diamonds or
rubies, alloyed gold being too soft to make a durable rubies, alloyed gold being too soft to make a durable
point. The discovery that the native alloy of iridium and osmium, one of the hardest and most refractory of all metallic alloys, could be used much more cheaply These iridium points are now imbedded in the gold, instead of being soldered on as was at first done.

Gold pens are made in a manner similar to steel pens, by rolling the metal into thin sheets and stamp ing out the blanks and shaping them with dies. The
gold is melted and alloyed to about 16 karats fine. The blunt nib of the blank is notched at the end to receive the iridium, which is coated with a cream of borax which is ground in water. The imbedding of the of "sweating," which consists in melting the gold of of "sweating," which consists in melting the gold of
which the pen is formed so that it unites solidly with the iridium. The blank is then passed between rollers
which give it a gradually diminishing thickness from which give it a gradually diminishing thickness from the point backward, the rolls having a small cavity in
which the extreme end of the iridium nib is placed to prevent injury to it.

The most important process in the manufacture of the gold pen is the hammering of the nib, in order to
stiffen it and render it springy or elastic. The slit is cut through the solid iridium by means of a thin copper wheel, after which it is extended up the pen itself, to the notch, with a saw. The pen is finished by polishing upon buff wheels.

Fountain pens-pens which have an ink barrel in the holder which supplies ink as required by means of an automatic feed-are the most modern and the high-
est type of art of the pen maker. They were not made est type of art of the pen maker. They were not made
in the United States until about 1880 . A fountain pen in the United States until about 1880 . A fountain pen
may be said to consist of four pieces of hard rubber and an ordinary gold pen. The handle containing the ink reservoir is in twc pieces, which are connected with a screw joint, which permits it to be taken apart readily for filling. The gold ren is held in the point section by a rubber ink feeder lying adjacent to it, to attract the ink from the reservoir. As the ink in the
process of writing is withdrawn, air enters at the process of writing is withdrawn, air enters at the
lower end of the holder and ascends in globules hrough the column of ink to fill the space left vacant.
The fourth piece of rubber is the cap, which covers the pen to protect it from injury and to keep the ink from drying when not in use. A fountain pen usually holds
ink enough for writing from 15,000 to 20,000 words ink enough for
without refilling.

whe rubber which goes into the making of fountain pens is the best obtainable, coming chiefly from Para, Brazil, and reaching the pen factory in chunks as large as a man's head. It is there first torn apart, washed, and then allowed to dry for several months. After
this it is rolled out, in shape like a sheet of iron, this it is rolled out, in shape like a sheet of iron,
sprinkled and rolled in sulphur, then vulcanized and made ready for working. In this condition it is nex rolled on steel cylinders, or mandrels, and placed in a steel heater for several hours. The metal rods are then withdrawn, leaving the empty cylinders, and the outside of the various parts are smoothed down with
lathes, polished, and made to fit one another by skilled workmen

The stylographic pen is a variety of fountain pen in which a blunt needle, which is incased in a sheath at
the end of the holder, serves as a valve to release the the end of the holder, serves as a valve to release the
ink when the point is pressed on the paper. There ink when the point is pressed on the paper. There
were about a million and a half of fountain and stylographic pens manufactured in the United States during 1905.

PRESERVATION OF FOODS.*

Various methods have been employed from time to time for the preservation of foods, first for the purof scansportation and second for use during times od, sincity. Long ago drying proved an effective methfor their growth and development. For some foods it is still desirable. For example, sweet corn, when properly dried and carefully cooked, is more palatable than canned corn. Raisins and prunes are examples of dried fruits, which are very palatable and wholesome. in salt or vind plan of preserving irults parts of sugar are all effective in keeping the fruit, but are which will destroy or prion to the fruit of anything most certainly prevent or retard digestion, for the ferments of the digestive juices are affected by prepisely the same things that affect germ life. However, ties by those of vigorous digestion without proving a great menace to the health. Much more to be condemned is the modern process of preserving by use of antiseptics, such as salicylic acid, which has been most flavor to the fruit and is detected with difficulty. It is, however, a very powerful drug and even when taken affects the heart and occasions other organic disturb-

All decay or fermentation of food substances is due to the action of germs. These microscopic organisms is kept in a cold, dry atmosphere, at about $40 \mathrm{deg}$. F. where currents of air are excluded, it may be preserved for a long time, since the germs of decomposition cannot grow rapidly in such an atmosphere. This method of keeping foods is known as refrigeration, bury fruit or vegatables in the ground or store them for a cool cellar. The boiling temperature continued life. Hence boiling fruit will ordinarily destroy germ where the germs present in the air cannot gain access, is an effective method of preservation, within the abilbeing eminently hygienic.

THE KEEPING QUALITIES OF FRUITS.

Fruits vary in keeping qualities. Those rich in acids are easily kept since the yeasts of fermentation do not grow readily in an acid solution. Tomatoes seldom spoil. The vegetables, peas, beets, asparagus, corn, considerable sugar, yet they may be satisfactorily considerable sugar, yet they may be satisfactorily
canned at home if the proper precautions are taken. Rhubarb contains enough oxalic acid to preserve it without cooking. Slice, put in a jar of cold boiled without cooking. Slice, put in a jar of cold boiled
water, fasten the lid, and it will keep indefinitely. Gooseberries, if not too ripe, may be treated in the same way. It is needless to say that fruits which will keep in this way are not altogether wholesome. The pineapple is an exception to most fruits in that it contains an enzyme (an unorganized ferment) like pepsin, which has the power of digesting albuminoids. sin, which has the power of digesting albuminoids,
milk, meat and eggs. It also destroys the yeasts which are the cause of fermentation. When properly canned are the cause of fermentation.
without sugar it keeps very well.

\section{PREPARATI $\bullet$ H $\bullet$ R CANNING.}

Select self-sealing cans of some good variety. Of the many kinds on the market the screw-top jar is good and not expensive. The Economy jar, recently
put on the market, is also good, though the necessity of buying new lids each time the jars are used is an appreciable expense. Some of the new screw-top jars are very defective. There may be dents around the
top where the rubber is fitted to the jar or. a rough edge at the top, making it very difficult and sometimes impossible to fit a lid to the jar. The first difficulty may sometimes be overcome by pressing the lid down moved by filing the edge of the jar with an ordinary file. Examine the jars before buying and reject those that are defective, since no dealer has a right to sell
such jars at the same price as good ones. Always use * Rocky Mountaun Farming. 